\title{
CYTOCHROME OXIDASE I GENE REVEALS POTENTIAL CRYPTIC DIVERSITY OF DOUBLEWHIP THREADFIN BREAM, Nemipterus nematophorus (BLEEKER, 1854) IN PENINSULAR MALAYSIA
}

\author{
TUN NURULAIMI MAT JAAFAR ${ }^{* 1}$, NURLIYANA SHARIFFUDDIN ${ }^{1}$, SALWANIABDULLAH $^{1}$, \\ AHASAN HABIB ${ }^{1,2}$ AND TAN MIN PAU ${ }^{3}$
}

${ }^{1}$ Faculty of Fisheries and Food Science, Universiti Malaysia Terengganu, 21030 Kuala Nerus, Terengganu, Malaysia. ${ }^{2}$ Department of Fisheries and Marine Sciences, Noakhali Science and Technology University, Noakhali-3814, Bangladesh. ${ }^{3}$ Institue of Marine Biotechnology, Universiti Malaysia Terengganu, 21030 Kuala Nerus, Terengganu, Malaysia.

*Corresponding author: tun_aimi@umt.edu.my

Submitted: 27 August $2019 \quad$ Accepted: 16 April 2020

http://doi.org/10.46754/jssm.2020.06.004

\begin{abstract}
Genetic variations and differences among three Nemipterus nematophorus populations in Peninsular Malaysia were evaluated based on partial sequence of the mitochondrial Cytochrome Oxidase I gene (654bp). Among the 30 individuals sampled, 12 putative haplotypes were detected, and $58 \%$ (7) of the haplotypes were unique with a high level of haplotype diversity $(\mathrm{H}=0.802)$ and low nucleotide diversity $(\boldsymbol{\pi}=0.0114)$. The constructed neighbour joining (NJ) phylogenetic tree based on haplotypes showed two clusters with specimens from Kelantan and Melaka grouped in the same cluster, while Terengganu samples formed an isolated cluster. These two clusters were separated with maximum $2.9 \%$ nucleotide divergence. Analysis of Molecular Variance (AMOVA) revealed a high level of $\mathrm{F}_{\mathrm{ST}}$ value $\left(\mathrm{F}_{\mathrm{ST}}=0.16 ; \mathrm{p}=0\right)$. Pairwise $\mathrm{F}_{\mathrm{ST}}$ value showed significant differences between the Kelantan and Melaka populations from the one in Terengganu. The Terengganu population, although morphologically identical with specimens from Kelantan and Melaka, consisted of a genetically discrete taxon. This study revealed that there is potential cryptic diversity of $N$. nematophorus in Peninsular Malaysia. These findings are important to provide a scientific framework for sustainable management strategies and conservation of commercially important fishery resources in the region.
\end{abstract}

Keywords: COI, cryptic diversity, Nemipterus nematophorus, Peninsular Malaysia.

\section{Introduction}

Malaysia is one of the biodiversity hotspots in Southeast Asia (Lim et al., 2016). Its inland and coastal waters are known as rich fish breeding habitats, and about $82 \%$ of Malaysia's national fish harvest comes from inshore fisheries (Lim et al., 2016). The studied species, the doublewhip threadfin bream or Nemipterus nematophorus (locally known as ikan kerisi dwifilamen), is a bottom-living coastal fish confined to tropical and sub-tropical waters of the Indo-West Pacific region (Hung et al., 2017). This species has been receiving increasing attention because of its commercial importance, specifically in the manufacture of surimi and surimi-based products (Santos \& Ng, 1993). Nemipterus nematophorus is available throughout the year and very popular with Malaysian consumers (Imtiaz et al., 2016). Threadfin breams are an important demersal fishery resource along the
Malaysian coast. They are mainly exploited by small commercial trawlers in depths up to 50 $\mathrm{m}$. The existence of rich resources of threadfin breams on the continental shelf beyond $50 \mathrm{~m}$ depth, especially in the 75 to $100 \mathrm{~m}$ belt along different parts of the shelf, often form $75 \%$ of the trawl catch (Joseph, 2000). However, threadfins bream catches are rarely reported because they are hard to identify (Pawar et al., 2011), and misidentification is a common problem at fish jetties and markets (Imtiaz et al., 2016).

Commercially important marine species may be particularly at risk in the loss of genetic diversity because population boundaries are often difficult to identify, migration patterns are not well described, and harvest may preferentially target specific population segments. Population genetic analysis is the best method to evaluate genetic divergence and plays vital role in getting information about the conservation 
genetics of a species (Xu et al., 2014)2014. It is also used to improve knowledge of the stock structure and can provide guidelines to optimize these practices and thus, conserve the genetic structure of $N$. nematophorus.

Molecular markers have been widely used in population genetics studies to identify fish stock structure and to infer population history (Sun et al., 2012; Habib \& Sulaiman, 2016). DNA markers are becoming more popular as well in obtaining gene flow information, allele frequencies and other parameters, which are crucial in population biology (Habib \& Sulaiman, 2016). Mitochondrial DNA (mtDNA) markers are more sensitive to demographic events that may affect genetic variation, such as reduction in population size and geographic isolation (Durand et al., 2005). Therefore, mtDNA has remained the marker of choice in many population, phylogenetic, phylogeographic and biogeographic studies (Hurst \& Jiggins, 2005). It is also widely used to investigate genetic variation between populations, population history, origin, migration or evolution (Lee et al., 2011). In the mitochondrial genome, the Cytochrome Oxidase-I gene (COI) is a recognized marker for genetic diversity detection and population genetic structures of marine fishes (Habib et al., 2011; Sun et al.,
2012; Xu et al., 2012; Xu et al., 2014; Mat Jaafar et al., 2019). COI is also appropriate for species identification, particularly the cryptic species (Imtiaz et al., 2016), and this has been used for both marine (Zhang, 2011; Mat Jaafar et al., 2012; Wang et al., 2012; Chang et al., 2017; Bakar et al., 2018) and freshwater fishes (Hubert et al., 2008; Barman et al., 2018; Rahman et al., 2019). The present study aimed to understand the population genetic structure and potential cryptic diversity of $N$. nematophorus along the coasts of Peninsular Malaysia for developing a sustainable management plan for this commercially important fishery resource based on COI gene as a marker.

\section{Materials and methods}

\section{Samples collection}

Samples of N.nematophorus were collected from fish markets and landing sites within Peninsular Malaysia (Melaka, Terengganu and Kelantan) as shown in Figure 1. Specimens of $\mathrm{N}$. nematophorus were identified using fish identification books (Ambak et al., 2010; Yoshida et al., 2013; Lim et al., 2018). This species could be differentiated from other Nemipterus species by its elongated first spine of dorsal fin and yellow filamentous upper lobe
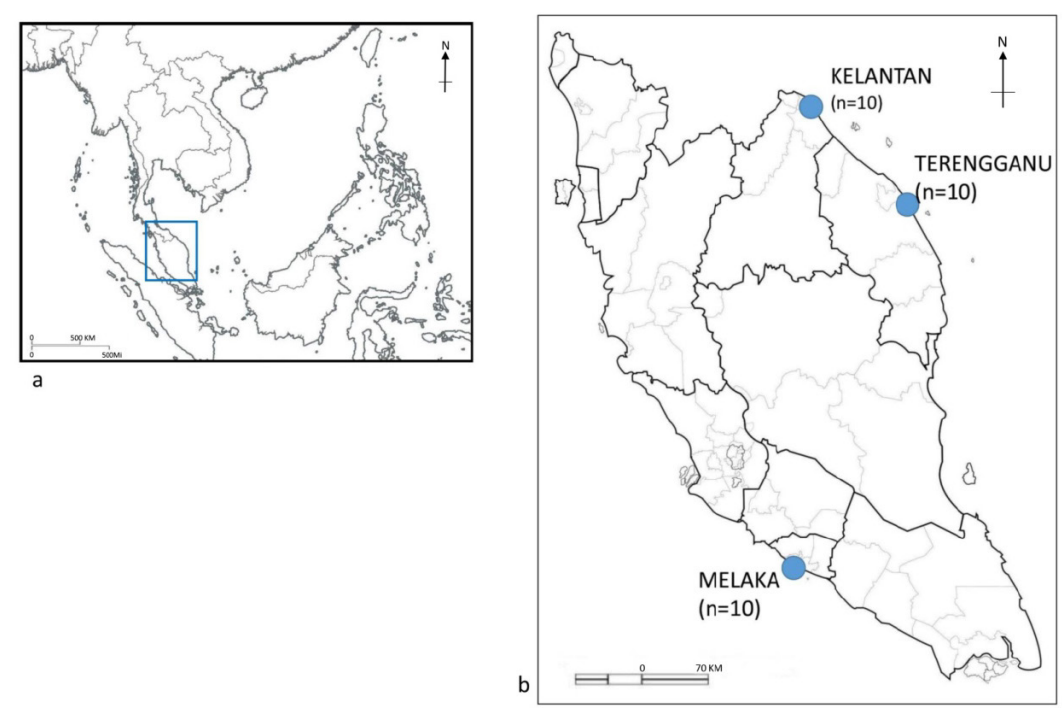

Figure 1: Sampling sites of N. nematophorus in (a) Peninsular Malaysia (marked with blue box in the map of Southeast Asia) and (b) sampling locations 
of the caudal fin (Yoshida et al., 2013). A total of 30 specimens were collected, with 10 individuals from each location. The right pectoral fin of the samples was preserved in $95 \%$ ethanol and kept at $-4^{\circ} \mathrm{C}$ until further analyses.

\section{DNA extraction and PCR amplification}

Total genomic DNA from each specimen was extracted using salt extraction methods according to Miller et al. (1988). The concentration and purity of the extracted DNA stock were determined using the Analytik Jena ScanDrop nano-volume spectrophotometer (Analytik Jena AG, Jena, Germany) before being stored in $1.5 \mu \mathrm{L}$ microcentrifuge tubes at $-20{ }^{\circ} \mathrm{C}$. PCR amplification of mtDNA COI was performed in $25 \mu \mathrm{L}$ solutions comprising $2.0 \mu \mathrm{L}$ of DNA extract, $0.3 \mu \mathrm{L}$ of forward and reverse primers $(10 \mathrm{mM}), 2.5 \mu \mathrm{L}$ of $10 \mathrm{X}$ PCR buffer, 2.0 $\mu \mathrm{L}$ of $\mathrm{MgCl}_{2}(50 \mathrm{mM}), 0.25 \mu \mathrm{L}$ of dNTP mix $(10 \mathrm{mM} / \mu \mathrm{L}), 0.20 \mu \mathrm{L}$ of Taq polymerase $(5 \mathrm{U} /$ $\mu \mathrm{L})$ and $17.45 \mu \mathrm{L}$ of pure distilled water. The sequences of the primers used were (FishF1) 5 ' T C A A C C A A C C A C A A A G A C AT T G GCAC3' and (FishR1) 5'TAGACTTCTGGGTG GCCAAAGAATCA3'(Ward et al., 2005).

The PCR reaction was performed using an Analytik Jena SpeedCycler (Analytik Jena AG, Jena, Germany) with the following program: three minutes (min) at $94{ }^{\circ} \mathrm{C}$ for initial denaturation, followed by 40 cycles of denaturing at $94{ }^{\circ} \mathrm{C}$ for 45 seconds, annealing at $53{ }^{\circ} \mathrm{C}$ for 45 seconds, and extension at $72{ }^{\circ} \mathrm{C}$ for 90 seconds, with a final five-minute extension at $72{ }^{\circ} \mathrm{C}$ before the process was terminated at $4{ }^{\circ} \mathrm{C}$ (Ward et al., 2005). The PCR products were visualized on a $1.2 \%(\mathrm{w} / \mathrm{v})$ agarose gel stained with SyBr Safe (Thermo Fisher Scientific, Waltham, MA, USA). The PCR products were sent for sequencing (First BASE Laboratories Sdn Bhd, Selangor, Malaysia) using forward primer only.

\section{Sequence editing and alignment}

All COI sequences were edited and aligned using ClustalW implemented in MEGA 6.0 (Tamura et al., 2013). The sequences were translated into amino acid sequences to ensure accurate alignment and no detection of numts. Confirmation of species identification were done by comparing all COI sequences with GenBank (http://blast.ncbi.nlm.nih.gov) (Benson et al., 2013) and BOLD system databases (www. boldsystems.org) (Ratnasingham \& Hebert, 2007) to avoid misidentification of specimens. Similarity thresholds of $99 \%$ were used to assign specimens to species level. All sequences were deposited into GenBank under the accession numbers MN808440 - MN808513.

\section{Data analyses}

The complete aligned dataset was analysed for genetic diversity, including number of haplotype, haplotype diversity (Hd) and nucleotide diversity $(\pi)$ using DnaSP6.0 (Rozas et al., 2017).

The Arlequin software package version 3.5.1.2 (Excoffier \& Lischer, 2010) was used to perform a hierarchical analysis of molecular variance (AMOVA) to examine population structure of $N$. nematophorus within the east and west coast of Peninsular Malaysia. The pairwise $F_{\mathrm{ST}}$ was generated to calculate relative genetic differentiation between populations based on Tamura-Nei distance method (Tamura \& Nei, 1993), and statistically significant pairwise comparisons were tested with 10,000 permutations (Xu et al., 2014)2014.

Neighbor-Joining (NJ) tree was constructed using MEGA6.0 and Caranx sexfasciatus (HQ560947) was included as out-group. The Kimura Two-Parameter (K2P) evolutionary distance (Kimura, 1980) was used with the NJ method and the confidence levels at each node were assessed by 10,000 bootstrap replications. A Maximum Likelihood (General Time Reversible model, GTR) (Nei \& Kumar, 2000) approach of the mitochondrial loci was conducted by determining the highest likelihood tree bootstrapped 10,000 times using RAxML 7.2.8 (Stamatakis et al., 2008). A network of all haplotypes was constructed by median joining calculation in Network 10.0.0.0 (Bandeltet al., 1999) to view the phylogeographic relationship 
among haplotypes.

\section{Results and Discussion}

\section{Species identification}

All 30 COI sequences in this study had been compared with sequences in GenBank with $99.7 \%$ similarity to $N$. nematophorus (MH235681, KY362838). Therefore, this confirmed that all specimens collected were correctly identified as $N$. nematophorus.

\section{Genetic diversity}

A total of 30 samples were assayed from three populations of $N$. nematophorus for the 654base pair (bp) COI sequence. No stop codons were observed, confirming that all amplified sequences constituted functional mitochondrial COI sequences. There were 21 polymorphic nucleotide sites, of which 16 were parsimony informative. Twelve unique haplotypes were identified with haplotypic diversity ranging from 0.511 to 0.889 (Table 1). Two haplotypes were recovered more than once. These two haplotypes (H_7 and H_10) were shared by samples from Kelantan and Melaka. While the other 10 haplotypes being singletons. The
Melaka population had the lowest haplotype (0.511) and nucleotide (0.00087) diversities, while Terengganu samples had the highest values at 0.889 and 0.00284 , respectively. Although all populations showed high haplotype diversity, low nucleotide diversity was also observed, ranging from 0.00087 to 0.00284 . This indicated that tehre were small genetic differences only between haplotypes.

The pairwise distance value between the three $N$. nematophorus populations ranged from $0.1 \%$ to $2.5 \%$. The Kelantan and Melaka populations were the closest at $0.1 \%$ nucleotide divergence, while Terengganu population was the most diverged with average pairwise nucleotide divergence of $2.45 \%$ (Table 2).

The analysis of mtDNA COI sequences of $N$. nematophorus from three distant populations identified 12 distinct haplotypes. The high level of haplotype diversity $(\mathrm{h}=0.802)$ and low nucleotide diversity were observed. Large and stable population size of marine fishes might lead to higher level of genetic diversity (Avise, 1998). In Peninsular Malaysia, N. nematophorus was one of the most extensively distributed and commonly landed fish species (Lim et al., 2016). So, its large population might support

Table 1: Distribution of haplotype frequencies in COI gene of Nemipterus nematophorus

\begin{tabular}{|c|c|c|c|c|c|c|c|c|c|c|c|c|c|c|c|}
\hline Haplotype & 1 & 2 & 3 & 4 & 5 & 6 & 7 & 8 & 9 & 10 & 11 & 12 & $\mathbf{n}$ & Hd & $\pi$ \\
\hline \multicolumn{16}{|l|}{ Localities } \\
\hline Terengganu & 2 & 1 & 2 & 3 & 1 & 1 & & & & & & & 10 & 0.889 & 0.00284 \\
\hline Kelantan & & & & & & & 6 & 1 & 1 & 1 & 1 & & 10 & 0.667 & 0.00125 \\
\hline Melaka & & & & & & & 7 & & & 2 & & 1 & 10 & 0.511 & 0.00087 \\
\hline Total & & & & & & & & & & & & & & 0.802 & 0.0114 \\
\hline
\end{tabular}

Symbols equal: $n$, sample size; Hd, haplotype diversity; $\pi$, nucleotide diversity

Table 2: Pairwise nucleotide distance (below diagonal); pairwise $F_{\mathrm{ST}}$ values (above diagonal) of COI gene between $N$. nematophorus populations

\begin{tabular}{llll}
\multicolumn{1}{c}{ Populations } & Terengganu & Kelantan & \multicolumn{1}{c}{ Melaka } \\
\hline Terengganu & & $0.2^{*}$ & $0.3^{*}$ \\
\hline Kelantan & 0.025 & & -0.05159 \\
\hline Melaka & 0.024 & 0.001 & \\
\hline
\end{tabular}

Symbol * showed significant pairwise $F \mathrm{ST}$ values $(\mathrm{P}<0.05)$ 
the high levels of haplotype diversity that was observed in this study. According to Grant and Bowen (1998), high haplotype diversity and low nucleotide diversity could also occur with the following two reasons: (i) a population experiencing bottleneck or about to go extinct, and (ii) allele losses followed by quick population growth from a small population, assuming that there was enough time for retrieval of haplotype variation through mutation.

Similar patterns had been reported for the Japanese threadfin bream (Nemipterus japonicus) (Lim et al., 2016), miiuy croaker (Miichthys miiuy) (Cheng et al., 2011; Xu et al., 2014)2014, crevalle jack (Caranx hippos) (Hernandez et al., 2018), white croaker (Pennahia argentata) (Han et al., 2008) and Crimson snapper (Lutjanus erythropterus) (Zhang et al., 2006). The population genetic study of $N$. japonicus also found low nucleotide diversity. The study explained that lower nucleotide diversity might occur due to the shallow shelf of Peninsular Malaysian coastal waters that had been recolonized by a reduced population of $N$. japonicus since the end of the last glacial maximum (Lim et al., 2016). For future adaptation, genetic diversity within and between populations provided a potential genetic resource, and could be critical for the suitability of a population (Hurt \& Hedrick, 2004). The gene flow across large spatial scales within Malaysia was indicated by the presence of shared haplotypes of samples at two distant locations, which were Kelantan and Melaka.

\section{Phylogenetic analysis, population genetic}

\section{structure and gene flow}

The NJ tree revealed two clusters of $N$. nematophorus (Figure 2). Mean K2P distance within species was $1.2 \%$, with a maximum of $2.9 \%$ nucleotide divergence. Cluster I consisted of populations from Melaka and Kelantan supported by $98 \%$ bootstrap value. While Cluster II comprised all individuals from Terengganu with $89 \%$ bootstrap value. The Maximum Likelihood (ML) tree also showed the same pattern (not shown).

For AMOVA, the variance among populations, among populations within groups and among groups relative to the total variance were $F_{\mathrm{ST}}=0.160, \mathrm{p}=0 ; F_{\mathrm{SC}}=0.251, \mathrm{p}=0.001$; $F_{\mathrm{CT}}=-0.123, \mathrm{p}=0.667$, respectively (Table 3 ). The result indicated a significant variation among the population and population within group. The pairwise $F_{\mathrm{ST}}$ values showed there were significant differentiations between Kelantan and Melaka populations with the Terengganu population. However, there was no significant difference detected between Kelantan and Melaka populations (Table 2). The median joining network based on nucleotide distance among haplotypes indicated two clades (Clade A \& B) (Figure 3), which was consistent with NJ and ML phylogenetic trees. Clade A consisted of haplotypes from Kelantan and Melaka and was separated from Clade B by numerous mutational steps. The Terengganu haplotypes included in Clade B and related to each other except for Hap06, which was isolated but still within Clade B. One intermediate hypothetical haplotypes (mv1) was detected, probable of haplotype extinction or un-sampled specimen. Seven of the haplotypes $(58 \%)$ are singletons, indicating a recent population expansion.

Table 3: Analysis of molecular variance (AMOVA) of N. nematophorus populations

\begin{tabular}{cccc}
\hline Source of variation & Percentage of variation & F-statistic & P-value \\
\hline Among group $\left(F_{\mathrm{CT}}\right)$ & 6.84 & -0.12195 & 0.66862 \\
\hline Among population within group $\left(F_{\mathrm{SC}}\right)$ & -0.12 & 0.25121 & 0.00098 \\
\hline Withinpopulations $\left(F_{\mathrm{ST}}\right)$ & 93.04 & 0.160 & 0 \\
\hline
\end{tabular}




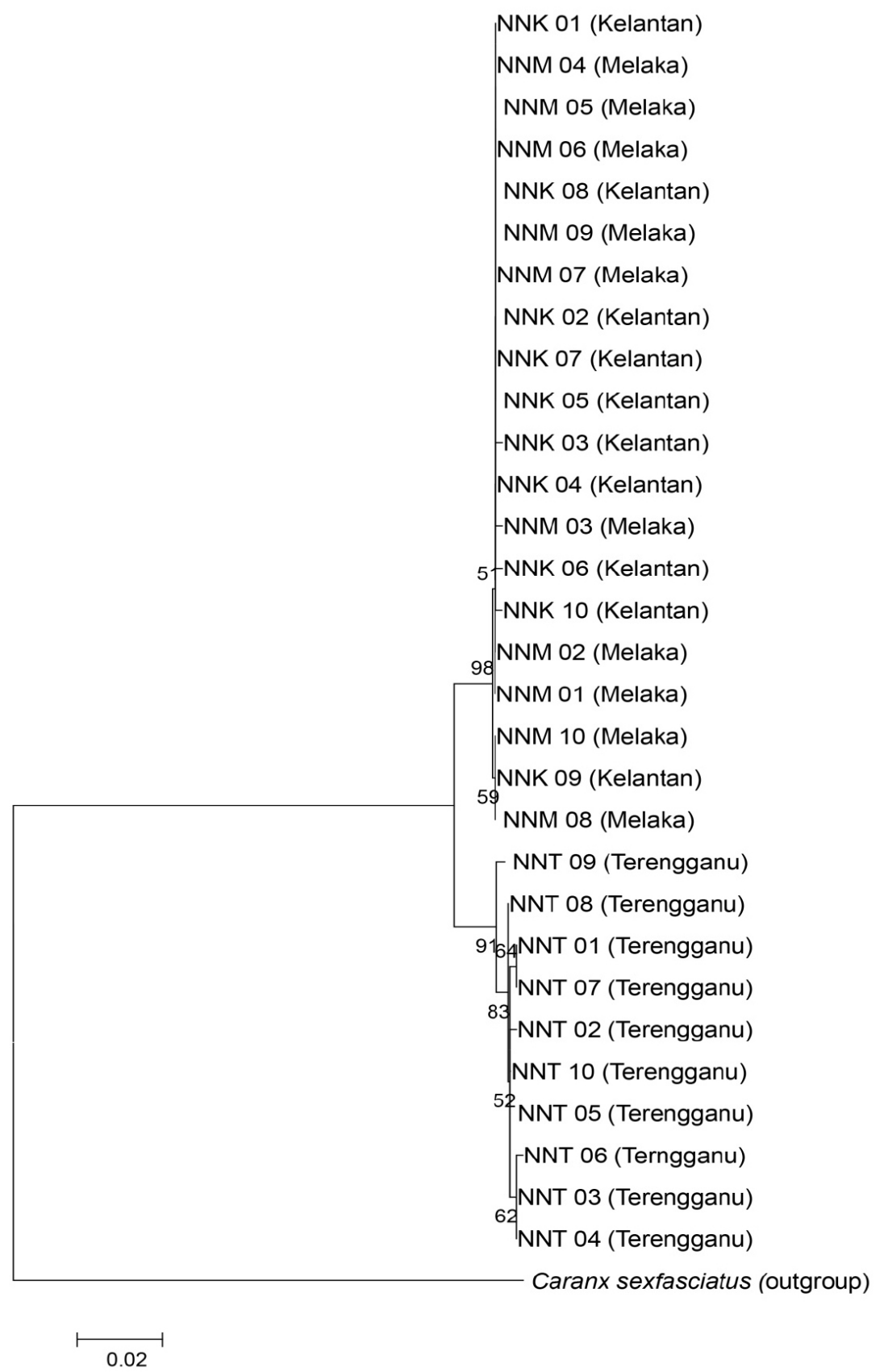

Figure 2: Neighbour joining tree (NJ) of $N$. nematophorus using the Cytochrome oxidase subunit I sequences. Only bootstrap values greater than 50 are shown 


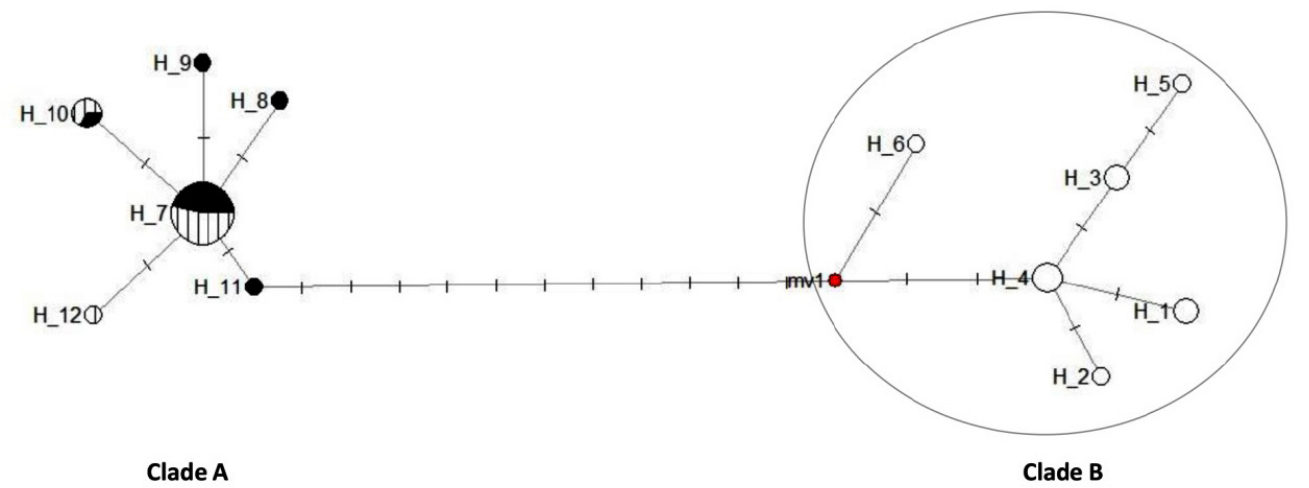

Figure 3: A minimum spanning network of COI gene haplotypes from N. nematophorus populations. Solid black represents haplotypes from Kelantan, solid white from Terengganu, vertical from Melaka. Crossbars on connecting line represents step of mutation between the haplotypes, mv is missing haplotypes linking the clades. Size of the circle is proportional to number of individuals

Marine fishes typically showed low levels of genetic differentiation in different geographical regions despite their high dispersal of potential planktonic egg, larval or adult history, along with the lack of physical barriers on movement between ocean basins or nearby continental margins (Avise et al., 1987; Rivera et al., 2004; $\mathrm{Xu}$ et al., 2014). Evidence from this study also showed that levels of genetic differentiation using $\mathrm{F}_{\mathrm{ST}}$ values inferred from COI marker were low in $N$. nematophorus, indicating extensive gene flow among distant populations. There were no barriers to gene flow from Melaka (west coast) to Kelantan (east coast), as specimens from these two localities were observed to share the same haplotype.

However, to confirm the occurrence of a single homogenous population of $N$. nematophorus within Malaysia waters, additional samples from other localities should be included in future studies. Similar results were found in $N$. japonicus, which was conducted in Peninsular Malaysia waters by Lim et al., (2016). They found that $N$.japonicus populations off the peninsula were panmictic, except a population in Kuala Besar, which was found to be a genetically discrete taxon from the rest. Mat Jaafar et al. (2019) also found no significant population subdivisions among bigeye scads (Selar crumenophthalmus) in Malaysian waters. In contrast, the other two Carangid species, the yellowtail scad (Atule mate) and yellowstripe scad (Selaroides leptolepis) showed significant differentiation among populations within this region. However, no geographic structuring was observed.

Although the current study indicated low genetic differentiation between $N$. nematophorus populations, a few studies have shown that population subdivisions did occur in marine fishes even across small spatial scales (Kakioka et al., 2018; Mat Jaafar et al., 2019). Some of the marine fishes consisted of discrete lineages within the same species due to the presence of geographic barriers and vicariance events in marine environment (Rocha et al., 2007; Drew \& Barber, 2009; Leray et al., 2010; Kakioka et al., 2018). In addition, genetic differentiation in some marine fishes had also been linked to circulation patterns and water exchanges between seas or oceans (Rohfritsch \& Borsa, 2005).

\section{Potential cryptic species}

Many species previously known to disperse widespread in marine environment could now be traced back to discrete lineages through the application of molecular methods (Lim et al., 2016; Imtiazet al., 2016; Mila et al., 2017; Bakar et al., 2018; Kakioka et al., 2018; Mat Jaafar et al., 2019). It had also become 
clear that the occurrences of cryptic species were quite common in marine environments (Lindstrom et al., 2012; Martinez-Takeshita et al., 2015; Lim et al., 2016; Bakar et al., 2018). This study observed two discreet lineages of $N$. nematophorus in Peninsular Malaysia with a mean K2P distance within species of $1.2 \%$ and a maximum of $2.9 \%$ nucleotide divergence. Cluster I consisted of samples from Melaka and Kelantan, while Cluster II comprised specimens from Terengganu only. However, no geographic pattern was apparent as Kelantan and Terengganu were in the northeast of Peninsular Malaysia, while Melaka was in the southwest. The genetic divergence among the three populations ranged from $0.1 \%$ to $2.5 \%$ with the largest differences seen between Kelantan and Melaka populations with Terengganu ones. The Terengganu population, although morphologically identical with specimens from Kelantan and Melaka, was composed of a genetically discrete taxon. This level of genetic divergence was consistent with the previous study of $N$. japonicus along the coasts of Peninsular Malaysia (Lim et al., 2016), which also found distinct cryptic species. Bakar et al., (2018) uncovered two different lineages among bigeye snappers (Lutjanus lutjanus) in Peninsular Malaysia. One of the lineages could represent an unrecognized or cryptic species. Mat Jaafar et al. (2019) also confirmed the existence of cryptic species among yellowtail scads in Malaysian waters. However, further examination on morphological characteristics would be required to confirm the new taxons.

\section{Conclusion}

Present study revealed the existence of potential cryptic diversity of $N$. nematophorus in Malaysian waters. The Terengganu population was very likely a different taxon from Kelantan and Melaka, but further investigations into its genetic characteristics, morphometrics, meristics and osteological characteristics were required to confirm and declare such new taxons. The evidence also showed that subdivisions exist in $N$. nematophorus populations in the coasts of Peninsular Malaysia and should be considered as different management units for effective conservation and management purposes. However, we only examined a single gene from mitochondrial DNA. The use of multiple genes, including nuclear markers, should be considered to increase the resolving power of genetic studies and for a better understanding on the population structure of $N$. nematophorus within this region.

\section{Acknowledgements}

The authors like to thank the Fisheries Department of Malaysia for the opportunity to participate in the National Demersal Trawl Survey expedition in 2016. The authors also thank Universiti Malaysia Terengganu for providing the logistics and financial support.

\section{References}

Ambak, M. A, Mat Isa, M., Zakaria, M. Z. \& Abd Ghaffar, M. (2010). Fishes of Malaysia. Penerbit Universiti Malaysia Terengganu: Kuala Terengganu, Malaysia. 333p.

Avise, J. (1998). Phylogeography. Harvard University Press: Cambridge, MA.

Avise, J. C., Arnold, J., Ball, R. M., Bermingham, E., Lamb, T., Neigel, J. E., Reeb, C. A., \& Saunders, N. C. (1987). Intraspecific phylogeography: the mitochondrial DNA bridge between population genetics and systematics. Annual Review of Ecology and Systematics, 18(1), 489-522.

Bakar, A. A., Adamson, E. A. S., Juliana, L. H., Nor Mohd, S. A., Wei-Jen, C., \& Man, A. (2018). DNA barcoding of Malaysian commercial snapper reveals an unrecognized species of the yellow-lined Lutjanus (Pisces: Lutjanidae). PLoS ONE, 13(9), e0202945.

Bandelt, H. J., Forster, P. \& Rohl, A. (1999). Median-joining networks for inferring intraspecific phylogenies. Molecular Biology and Evolution, 16, 37-48.

Barman, A. S., Singh, M., \& Singh, S. K. (2018). DNA barcoding of freshwater fishes of Indo-Myanmar biodiversity hotspot. Scientific Reports, 8, 8579. 
Benson, D. A., Cavanaugh, M., Clark, K., Karsch-Mizachi, I., Lipman, D. J., \& Ostell, J. (2013). Gen-Bank. Nucleic Acids Research, 41, 1-7.

Chang, C. H., Shao, K. T., Lin, H. Y., Chiu, Y. C., Lee, M. Y., Liu, S. H. \& Lin, P. L., (2017). DNA barcodes of the native rayfinned fishes in Taiwan. Molecular Ecology Resources, 17(4), 796-805.

Cheng, Y., Jin, X., Shi, G., Wang, R., \& $\mathrm{Xu}, \quad$ T. (2011). Genetic diversity and population structure of miiuy croaker populations in East China Sea revealed by the mitochondrial DNA control region sequence. Biochemical Systematics and Ecology, 39(4-6), 718-724.

Drew, J., \& Barber, P. H. (2009) Sequential cladogenesis of the reef fish Pomacentrus moluccensis(Pomacentridae) supports the peripheral origin of marine biodiversity in the Indo-Australian archipelago. Molecular Phylogenetics and Evolution, 53, 335-339.

Durand, J., Collet, A., Chow, S., Guinand, B., \& Borsa, P. (2005). Nuclear and mitochondrial DNA markers indicate unidirectional gene flow of Indo-Pacific to Atlantic bigeye tuna (Thunnus obesus) populations, and their admixture off southern Africa. Marine Biology, 147(2), 313-322.

Excoffier, L., \& Lischer, H. E. (2010). Arlequin suite ver 3.5: a new series of programs to perform population genetics analyses under Linux and Windows. Molecular Ecology Resources, 10(3), 564-567.

Grant, W., \& Bowen, B. (1998). Shallow population histories in deep evolutionary lineages of marine fishes: insights from sardines and anchovies and lessons for conservation. Journal of Heredity, 89(5), 415-26.

Habib, A., \& Sulaiman, Z. (2016). High genetic connectivity of narrow-barred Spanish mackerel (Scomberomorus commerson) from the South China, Bali and Java Seas. Zoology and Ecology, 26(2), 93-99.
Habib, K. A., Jeong, D., Myoung, J. G., Kim, M. S., Jang, Y. S., Shim, J. S., \& Lee, Y. H. (2011). Population genetic structure and demographic history of the fat greenling Hexagrammos otakii. Genes \& Genomics, 33(4), 413-423.

Han, Z.-Q., Gao, T.-X., Yanagimoto, T., \& Sakurai, Y. (2008). Deep phylogeographic break among white croaker Pennahia argentata (Sciaenidae, Perciformes) populations in North-western Pacific. Fisheries Science, 74(4), 770-780.

Hernandez, I. C., Barandica, J. N. \& Pizzaro, A. A. (2018) Genetic variation and genetic structure of Caranx hippos (Teleostei: Carangidae) in the Colombian Caribbean. Revista de Biological Tropical. doi: 10.15517/rbt.v66i1.25770

Hung, K. W., Russell, B. C., \& Chen, W. J. (2017). Molecular systematics of threadfin breams and relatives (Teleostei, Nemipteridae). Zoologica Scripta, 46(5), 536-551.

Hurst, G. D., \& Jiggins, F. M. (2005). Problems with mitochondrial DNA as a marker in population, phylogeographic and phylogenetic studies: the effects of inherited symbionts. Proceedings of the Royal Society B: Biological Sciences, 272(1572), 1525-1534.

Hurt, C., \& Hedrick, P. (2004). Conservation genetics in aquatic species: General approaches and case studies in fishes and springsnails of arid lands. Aquatic Sciences, 66(4), 402-413.

Hubert, N., Hanner, R., Holm, E., Mandrak, N. E., Taylor, E., Burridge, M., Watkinson, D., Dumont, P., Curry, A. \& Bentzen, P., (2008). Identifying Canadian freshwater fishes through DNA barcodes. PloS One, 3(6), e2490.

Imtiaz, A., Yen, D. T., Nor, S. A. M., \& Naim, D. M. (2016). Molecular identification of commercially important species of Nemipterus (Perciformes: Nemipteridae) in surrounding seas of Malaysia. Biodiversitas Journal of Biological Diversity, 17(2), 571-577. 
Joseph, J. (2000). Intraspecific and interspecific studies in Nemipterus (Pisces: Perciformes: Nemipteridae) using truss network analysis and protein gel electrophoresis: Central Marine Fisheries Research Institute, pp 86.

Kakioka, R., Muto, N., \& Takeshima, H. (2018). Cryptic divergence in Scolopsistaenioptera (Perciformes: Nemipteridae) in the western Pacific Ocean. Ichthyological Research, 65, 92-100. https://doi.org/10.1007/s10228017-0596-1

Kimura, M., (1980). A simple method for estimating evolutionary rates of base substitutions through comparative studies of nucleotide sequences. Journal of Molecular Evolution,16(2), 111-20.

Lee, J. C., Tsai, L. C., Lin, C. Y., Linacre, A., \& Hsieh, M. (2011). The distribution of mitochondrial D-loop sequence variations in Taiwan populations. Forensic Science Journal, 10(1), 29-38.

Leray, M., Beldade, R., Holbrook, S. J., Schmitt, R. J., Planes, S., \& Bernardi, G. (2010) Allopatric divergence and speciation in coral reef fish: the three-spot dascyllus, Dascyllustrimaculatus, species complex. Evolution, 64,1218-1230.

Lim, A. P. K., Ahmad, A., Nor Azman, Z., \& Mohd Saki, N. (2018). Field Guide to Fishes and Crustaceans of the Southeast Asian Region. SEAFDEC/MFRDMD/39: Malaysia. 246p

Lim, H.-C., Ahmad, A. T., Nuruddin, A. A., \& Mohd Nor, S. A. (2016). Cytochrome $b$ gene reveals panmixia among Japanese Threadfin Bream, Nemipterus japonicus (Bloch, 1791) populations along the coasts of Peninsular Malaysia and provides evidence of a cryptic species. Mitochondrial DNA, 27(1), 575-584.

Lindstrom, D. P., Blum, M. J., Walter, R. P., Gagne, R. B., \& Gilliam, J. F. (2012). Molecular andmorphologicalevidence of distinct evolutionary lineages of Awaous guamensis in Hawai'i and Guam. Copeia, 2012, 293-300.
Martinez-Takeshita, N., Purcell, C. M., Chabot, C. L., Craig, M. T., Paterson, C. N., Hyde, J. R., \& Allen, L. G. (2015). A tale of three tails: cryptic speciation in a globally distributed marine fish of the genus Seriola. Copeia, 103(2): 357-368.

Mat Jaafar, T. N. A., Taylor, M. I., Mhd Nor, S. A., de Bruyn, M., \& Carvalho, G. R. (2019). Comparative genetic stock structure in three species of commercially exploited IndoMalay Carangidae (Teleosteii, Perciformes). Journal of Fish Biology, 2019, 1-13. https:// doi.org/10.1111/jfb.14202

Mat Jaafar, T. N. A., Taylor, M. I., Mhd Nor, S. A., de Bruyn, M., \& Carvalho, G. R. (2012). DNA barcoding reveals cryptic diversity within commercially exploited Indo-Malay Carangidae (Teleosteii: Perciformes). PLoS ONE, 7(11), e49623.

Mila, B., Van Tassell, J. L., Calderon, J. A., Ruber, L., \& Zardoya, R. (2017). Cryptic lineage divergence in marine environments: genetic differentiation at multiple spatial and temporal scales in the widespread intertidal goby Gobiosoma bosc. Ecology and Evolution, 7, 5514 - 5523. https://doi. org/10.1002/ece3.3161.

Miller, S. A., Dykes, D. D., \& Polesky, H. F. (1988). A simple salting out procedure for extracting DNA from human nucleated cells. Nucleic Acids Research, 16, 1215.

Nei, M., \& Kumar, S., (2000). Molecular evolution and phylogenetics. Oxford University Press, New York.

Pawar, H., Shirdhankar, M., Barve, S., \& Patange, S. (2011). Discrimination of Nemipterus japonicus (Bloch, 1791) stock from Maharashtra and Goa states of India. Indian Journal of Geo-Marine Sciences, 40(3), 471-475.

Rahman, M. M., Noren, M., Mollah, A. R., \& Kullander, S. O. (2019). Building a DNA barcode library for freshwater fishes of Bangladesh. Scientific Reports, 9, 9382. 
Ratnasingham, S., \& Hebert, P. D. N. (2007). BARCODING BOLD: The Barcode of Life Data System. Molecular Ecology Notes, 7, 355-364.

Rivera, M. A. J., Kelley, C. D., \& Roderick, G. K. (2004). Subtle population genetic structure in the Hawaiian grouper, Epinephelus quernus (Serranidae) as revealed by mitochondrial DNA analyses. Biological Journal of the Linnean Society, 81(3), 449-468.

Rocha, L. A., Craig, M. T., \& Bowen, B. W. (2007) Phylogeography and the conservation of coral reef fishes. Coral Reefs, 26, 501-512.

Rohfritsch, A., \& Borsa, P. (2005) Genetic structure of India scad mackerel Decapterus russelli: Pleistocene vicariance and secondary contact in the central Indo-West Pacific seas. Heredity, 95, 315-326.

Rozas, J., Ferrer-Mata, A., Sánchez-Delbarrio, J. C., Guirao-Rico, S., Librado, P., RamosOnsins, S. E., \& Sánchez-Gracia, A. (2017). DnaSP 6: DNA sequence polymorphism analysis of large data sets. Molecular Biology and Evolution,34(12), 3299-3302.

Santos, E., \& Ng, C. (1993). Evidence for genetic variation in the sarcoplasmic protein of Nemipterus peronii (Valenciennes). Asian Fisheries Science, 6, 265-270.

Stamatakis, A., Hoover, P., \& Rougemont, J. (2008). A rapid bootstrap algorithm for the RAxML web servers. Systematic Biology, 57(5), 758-771.

Sun, P., Shi, Z. H., Yin, F., \& Peng, S. M. (2012). Genetic variation analysis of Mugil cephalus in China Sea based on mitochondrial COI gene sequences. Biochemical Genetics, 50(3-4), 180-191.

Tamura, K., Stecher, G., Peterson, D., Filipski, A., \& Kumar, S. (2013). MEGA6: molecular evolutionary genetics analysis version 6.0. Molecular Biology and Evolution, 30(12), 2725-2729.
Tamura, K., \& Nei, M., (1993). Estimation of the number of nucleotide substitutions in the control region of mitochondrial DNA in humans and chimpanzees. Molecular Biology and Evolution, 10(3), 512-26.

Ward, R. D., Zemlak, T. S., Innes, B. H., Last, P. R., \& Hebert, P. D. (2005). DNA barcoding Australia's fish species. Philosophical Transactions of the Royal Society B: Biological Sciences, 360(1462), 18471857.

Wang, Z.-D., Guo, Y.-S., Liu, X.-M., Fan, Y.B., \& Liu, C.-W., (2012). DNA barcoding South China Sea fishes. Mitochondrial DNA, 23(5), 405-10.

Xu, D., Lou, B., Shi, H., Geng, Z., Li, S., \& Zhang, Y. (2012). Genetic diversity and population structure of Nibea albiflora in the China Sea revealed by mitochondrial COI sequences. Biochemical Systematics and Ecology, 45, 158-165.

Xu, H., Zhang, Y., Xu, D., Lou, B., Guo, Y., Sun, X., \& Guo, B. (2014). Genetic population structure of miiuy croaker (Miichthys miiuy) in the Yellow and East China Seas base on mitochondrial COI sequences. Biochemical Systematics and Ecology, 54, 240-246.

Yoshida, T.H., Motomura, H., Musikasinthorn, P., \& Matsuura, K. (eds). (2013) Fishes of Northern Gulf of Thailand. National Museum of Nature and Science, Tsukuba, Research Institute of Humanity and Nature, Kyoto and Kagoshima University Museum, Kagoshima.

Zhang, J., Cai, Z., \& Huang, L. (2006) Population genetic structure of crimson snapper Lutjanuserythropterus in East Asia, revealed by analysis of the mitochondrial control region. ICES Journal of Marine Science, 63, 693-704.

Zhang, J., (2011). Species identification of marine fishes in China with DNA barcoding. Evidence-Based Complementary and Alternative Medicine,2011, Article ID 978253, 10 pages doi:10.1155/2011/978253 